\title{
Improving Outdoor Activity in China's Newly Developed Residential Communities?
}

\author{
Qing Yin 1 , Ryuzo Ohno² \\ Department of Built Environment, \\ Tokyo Institute of Technology \\ iiixixiyiyi@gmail.com, rohno@n.cc.titech.ac.jp
}

\begin{abstract}
Evidences suggested outdoor activities in newly developed communities in China have become less active than older ones. Improving outdoor activities by physical environment is the major concern of this research. This paper used a basic social-ecological model to explain the mechanism of outdoor activities in China. An intensive survey was carried out to examine how environmental factors affect outdoor activities. 7668 users' activity data were obtained by observation, and the activities observed were categorized into three groups concerning environment involvement. The result suggested that some factors such as accessibility, environment supports are linked to outdoor activities in China.
\end{abstract}

Keywords: Outdoor activity; physical environment; residential community; social network

eISSN 2398-4295 @ 2018. The Authors. Published for AMER ABRA cE-Bs by e-International Publishing House, Ltd., UK. This is an open-access article under the CC BY-NC-ND license (http://creativecommons.org/licenses/bync-nd/4.0/). Peer-review under responsibility of AMER (Association of Malaysian Environment-Behaviour Researchers), ABRA (Association of Behavioural Researchers on Asians) and cE-Bs (Centre for EnvironmentBehaviour Studies), Faculty of Architecture, Planning \& Surveying, Universiti Teknologi MARA, Malaysia.

DOI: http://dx.doi.org/10.21834/ajbes.v3i12.127 


\subsection{Introduction}

Communities have changed drastically since the Chinese government initiated a commodity housing policy in 1998. Prior to this policy, most Chinese citizens from the same company lived houses provided by governmental organizations within a single community. After the policy, new communities were developed as commodities, and many people from different backgrounds rushed into the city to buy these houses. The social interactions with neighbors in these communities have drastically decreased due to the increased diversity and unfamiliarity with neighbors. Because outdoor activities promote social interactions and mutual support between neighbors, which help maintain the residents' physical and mental health and prevent crime within a community, it is important to improve outdoor activities in newly developed communities in China.

There is increasing interesting in the role that physical environment plays in promoting activities (Abd-Latif et al., 2012). Several pathways have been proposed to explain the significance of the physical environment in people's activities (Zhang \& Li, 2011). Many researchers have argued that walkable environment supports certain outdoor activities such as walking, exercising, etc. (Alfonzo, 2005; Frank et al., 2006; Shamsuddin, Hassan, \& Bilyamin, 2012). Some significant environmental factors related to activity have been discussed such as accessibility, safety, comfort, and so on (Alfonzo, 2005). However, most of the previous researches focus on physical activity. Researches about outdoor activities still remain in the early stages.

In this paper, we analyze outdoor activities after categorizing them concerning environment involvement. A social-ecological model was developed to explain the mechanism of outdoor activity needs that synthesized what is known about the relations between environment and activity. Systematic observation was conducted to analyze how physical environment affect outdoor activities. A total of 7668 users' activity data was obtained. This paper aims to explore the relationships between significant environmental factors and outdoor activities, and point a direction for improving outdoor activity in China.

\subsection{Literature Review}

\subsection{Categorization of outdoor activities}

Although there is no definition of "activity" that is universally agreed upon by social scientists, several researchers defined their activities in terms of research needs. For instance, one of widely concerned activities is physical activity. Several researchers emphasized the positive action of physical activity on the health problems such as obesity, psychological illness, etc. (Carlier, Delevoye-Turrell, \& Dione, 2014). They defined physical activity from the view of physical intensity. Since our objective is to explore the relationships between significant environmental factors and outdoor activities, the activities determined in this paper should be associated with environment.

Hanazato and Kim (2011) grouped outdoor activities into Pass and Stay activities. In the former a user traverses through a space, whereas in the latter a user stops in or remains in a space. They argued that Stay activities are more related to the social life, and some 
activities such as stroll may related to the social life. Therefore, we divided outdoor activities into three groups by the degree of environment involvement which associated with social life. Table 1 shows the categorization of outdoor activities, including passing-by related activities, strolling related activities, and staying related activities. We name the tree categories Pass, Stroll, and Stay respectively.

Table 1: Categorization of outdoor activities

\begin{tabular}{|c|c|c|c|c|}
\hline Category & Environmental involvement & Subcategory & Examples & Symbol \\
\hline \multirow{3}{*}{$\begin{array}{l}\text { Passing-by } \\
\text { related } \\
\text { codes } \\
\text { (Pass) } \\
\end{array}$} & \multirow{3}{*}{$\begin{array}{l}\text { Participants are little concern } \\
\text { about the environmental } \\
\text { quality; they use the space as } \\
\text { a path to the destinations. }\end{array}$} & Walking by & Walking, running & \\
\hline & & Cycling by & Cycling & \\
\hline & & Driving by & Driving & \\
\hline \multirow{2}{*}{$\begin{array}{l}\text { Strolling } \\
\text { related } \\
\text { codes } \\
\text { (Stroll) }\end{array}$} & \multirow{2}{*}{$\begin{array}{l}\text { Participants may enjoy then } \\
\text { environmental quality while } \\
\text { strolling through the space on } \\
\text { foot. }\end{array}$} & No pause & $\begin{array}{l}\text { Jogging, walking the } \\
\text { dog, sightseeing etc. }\end{array}$ & \\
\hline & & $\begin{array}{c}\text { Temporary } \\
\text { pause }\end{array}$ & $\begin{array}{l}\text { Short meeting, } \\
\text { reading notice etc. }\end{array}$ & \\
\hline \multirow{2}{*}{$\begin{array}{l}\text { Staying } \\
\text { related } \\
\text { codes } \\
\text { (Stay) }\end{array}$} & \multirow{2}{*}{$\begin{array}{l}\text { Participants do some things } \\
\text { or stay inside the space, they } \\
\text { do the activities supported by } \\
\text { the environment. }\end{array}$} & $\begin{array}{l}\text { Sedentary } \\
\text { activity }\end{array}$ & $\begin{array}{l}\text { Sitting, standing, } \\
\text { playing cards etc. }\end{array}$ & \\
\hline & & $\begin{array}{l}\text { Vigorous } \\
\text { activity }\end{array}$ & $\begin{array}{l}\text { Chasing, excising, } \\
\text { dancing etc. }\end{array}$ & \\
\hline
\end{tabular}

\section{2,2 Basic social-ecological model}

The term environment usually refers to climate, weather, downtown, the suburbs, traffic congestion, neighborhoods, industrial districts, lakes, rivers, skyscrapers, pollution, acid rain, and many other aspects of the natural and built surroundings (Schoggen, 1968). In this research our objective is more similar with Roger Barker's ecological environment (1968). Barker's ecological theories are describable in the framework of dynamical systems theory, and environment-behavior theories reached a higher level. The purpose of this research is simple that is to recover the relationships between physical environment and outdoor activities. Therefore before the field survey it is necessary to develop a social-ecological model to scope components.

Notably Alfonzo (2005) proposed a social-ecological model of walking. He explicitly elaborated inner links between walking and environment. This model emphasized the decision of walking, which cannot be used in different action studies. Franzini (2010) modified Alfonzo's model for outdoor physical activity. He considered social environment, as well as physical environment play an important role in outdoor physical activity. Based on the two models, we proposed a social-ecological model to explain the environmental factors in the decision to be active outdoors (Fig. 1). 


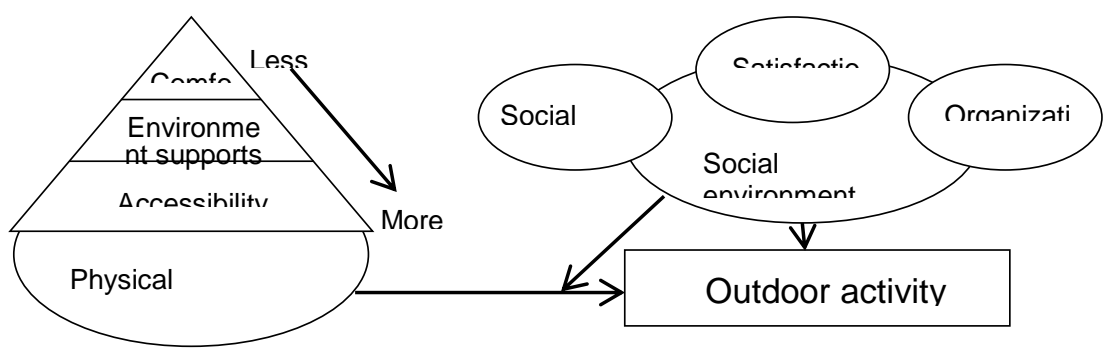

Figure 1: Basic social-ecological model of outdoor activity (Source: Modified from the model by Franzini et al.,2010)

Franzini (2010) considered that accessibility, safety, comfort, and pleasurability are the important physical environmental factors. In this paper, factors explicitly linked to the decision of outdoor activities have been modified according to China's condition. Three physical environmental factors are proposed. They are accessibility, environment supports, and comfort.

Some factors supposed to be more fundamental than others when deciding to be active outdoors in China. At the most fundamental level, there must be accessible spaces. Accessibility links to outdoor activity that incorporates elements such as the sidewalk length, convenience of approaches (Oloumi, Mahdavinejad, \& Namvarrad, 2011). At the next level, the decision to be active outdoors may depend on environment supports of the space, which reflects land property, and the presence of facilities. Environment supports can be perceived as affordance in this paper, which refers to the functionally significant properties of the environment (Kytta, 2003). At the last level, outdoor activities may be more likely to occur in environments that are comfort which is decided by elements such as microclimate (Nasir, Ahmad, \& Ahmed, 2013).

The decision to be active outdoors is decided not only by physical environment but may be moderated by the social environment. Many studies suggested that the social capital, satisfaction with neighborhoods, and organization program are outstanding factors in social environment (Honold, Wippert, \& Meer, 2014; Mohit \& Azim, 2012; Laurens, 2012). In present paper we focus on the role of physical environmental factors.

\subsection{Methodology}

An intensive field survey was carried out in China to examine the significance of physical environmental factors in newly developed residential communities. This field survey aims to collect direct first-hand information of outdoor activities, and aggregate effective data for analysis.

\section{Survey sites}

As one of the first batches of cities implemented the commodity housing policy, Tianjin is chosen as the survey site for it has developed many new residential communities. In this 
survey, our objects are residents' outdoor activities and outdoor physical environment. Hence the communities selected should be markedly different in physical environment and outdoor activities, which are the criteria of selection.

Prior to visiting the individual sites, aerial photographs of each site were examined to identify the physical environment of outdoor spaces. We found there are two basic layouts of outdoor spaces: the outdoor space distribution and the traffic network pattern. From these characteristics, we identified two typical types of space organization. The first has an even distribution of outdoor spaces connected by pedestrian paths that are not disturbed by peripheral motorways. The second type has a large central outdoor space surrounded by smaller spaces that are separated by motorways. Based on these two aspects, 7 candidate communities were selected.

Then we conducted a preliminary survey to examine outdoor activities. We divided outdoor space of each candidate community into many subspaces, and recorded their typical outdoor activities. Then we pieced the qualitative data together, and discussed the differences between the candidate communities. Eventually, four representative communities were selected.

Because observing all outdoor spaces in these four communities is not feasible and many outdoor spaces are similar, the next step was to select representative spaces to observe. Firstly we divided each community's open space into 20-40 subspaces defined by building walls and/or edge of wide roads. A total of 111 subspaces were obtained. A brief observation was conducted using the check form shown in Fig. 2 to collect activity and physical information of subspaces.

\section{NO.1 ACTVITY \& space croex pols

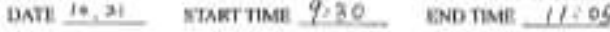

\begin{tabular}{|c|c|c|c|c|c|}
\hline & \multicolumn{2}{|c|}{ MUMmen } & ACTVITY TYPII & MIYSECAL CONDITION & COMMENTS \\
\hline \multirow{15}{*}{$\begin{array}{l}\text { ourocon } \\
\text { smax. }\end{array}$} & \multirow{5}{*}{ Consustity $\mathrm{A}$} & At & Wiloy by, Golis, theng & generr wix gnes, Likng, pway & A wuy mired wlowis bue \\
\hline & & At & 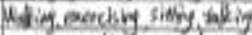 & 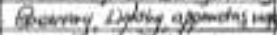 & S Syari an foyody wad \\
\hline & & M & Wally telkiog mandy. & 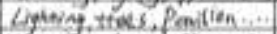 & A phe with ardsex. \\
\hline & & ad & Sirim strollig owering & 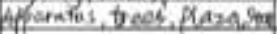 & Paeple like te stay thare \\
\hline & & - & & & \\
\hline & \multirow{5}{*}{ Comnerity 8} & HII & Wakig by Geliy ofiving & Lyboing, parking Toses & Werk as tod \\
\hline & & B-4 & 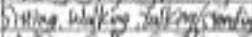 & 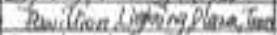 & heoph sen dop sier for \\
\hline & & B. & Wakivg gring, straling & Benchas. Ligive Ines.iva & Beat the lage \\
\hline & & 1.4. & Doncing laying sondoset. & 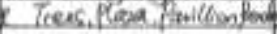 & Alpare fer pasple \\
\hline & & $\pi$ & & & \\
\hline & \multirow{5}{*}{ Cusmatise } & $c-1$ & Priatiogrealing friting & 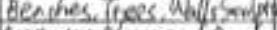 & A galet pace \\
\hline & & $c 4$ & 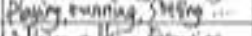 & 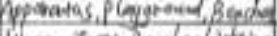 & En oxydien. \\
\hline & & $c 3$ & Solking ta king trasirg. & 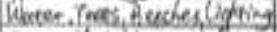 & Nait lake. \\
\hline & & ct & dalkeg by Cycliay - & Trees dattins cogloing & A road (Iust) \\
\hline & & $=$ & & & \\
\hline
\end{tabular}

Figure 2: An example of activity \& space check form

Subspaces with similar characteristics were grouped together and one representative subspace was selected from each group. Thus, the intensive survey involved 33 subspaces (Fig.3). 


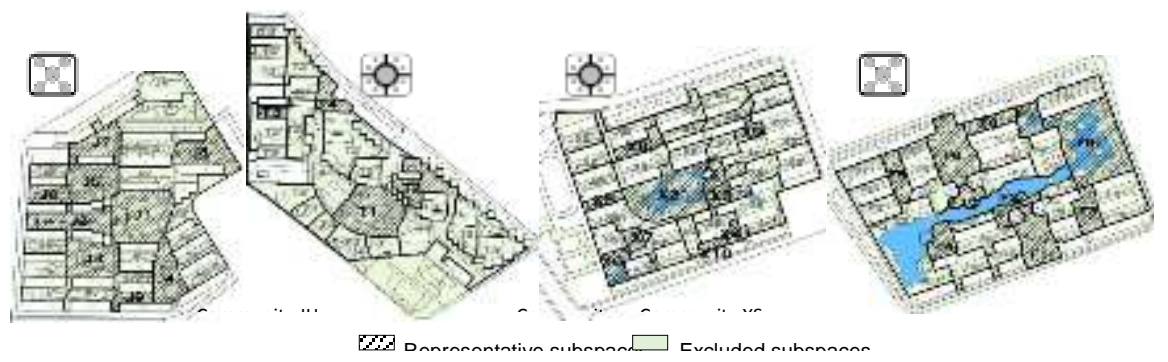

Figure 3: Subspaces selected in the four communities

The intensive survey had two steps: record the physical environment and observe the outdoor activities. The physical data for each subspace were recorded onto a physical environment check sheet shown in the left diagram of Fig. 5 . Then the activity data were recorded using an activity observation sheet, which is a synthesized tool for behavioral mapping and SOPARC (System for observing play and recreation in communities, McKenzie $\&$ Cohen, 2006) in the right diagram of Fig. 4.

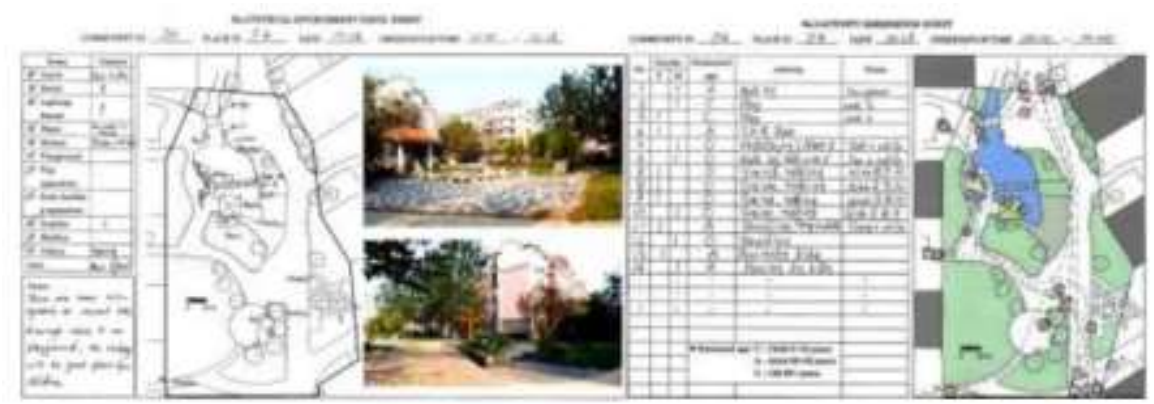

Figure 4: An example of physical environment check sheet and activity observation sheet

(Source: The right sheet modified from the observation form by Mckenzie, \& Cohen,2010)

Usually one piece of activity observation sheet is used for recording activities occurred in 10 minutes. The observation time may be varied up to 20 minutes according to the size of subspaces. The observations of every single subspace were carried out 5 days ( 3 working days +2 off days) in the morning and afternoon totally 10 times.

\subsection{Results and Discussions}

A total of 7668 users' activity data were obtained from 330 activity observation sheets (33 subspace $\times 10$ times). Table 2 shows the details of data. Besides, 33 physical environment sheets were obtained. The next step is using these data to analyze the relationships between environmental factors and outdoor activities. 
Table 2: Results of activity observation

\begin{tabular}{c|c|c|c}
\hline \multicolumn{2}{c|}{} & $\mathrm{N}$ & $\%$ \\
\hline Gender & Female & 3649 & 47.6 \\
& Male & 4019 & 52.4 \\
\hline \multirow{2}{*}{ Estimated age } & $0-19$ & 1104 & 14.4 \\
& $20-59$ & 4242 & 55.3 \\
& $60+$ & 2322 & 30.3 \\
\hline Category & Passing-by related code (Pass) & 4632 & 60.0 \\
& Walking related code (Stroll) & 949 & 12.4 \\
& Staying related code (Stay) & 2087 & 27.6 \\
\hline Total & & 7668 & 100 \\
\hline
\end{tabular}

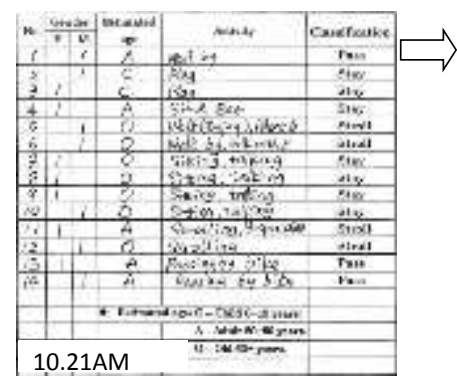

Figure 5: An example of

\begin{tabular}{|c|c|c|c|c|c|c|c|c|c|c|c|c|}
\hline ....Date... & G. & A. & .0 & T. .... Date .... & - & $A$. & . ه. & .7..... Date... & . . E. & A. & . & Total \\
\hline "OOLAAM" & " & 3 & $0 "$ & " 10.2IA"M" " & 0 & "1" & 3 & "10:2IA"M" " & 2 & "1" & $" 4 "$ & 7 \\
\hline $10.22 \mathrm{PM}$ & 1 & 2 & 5 & $10.22 \mathrm{PM}$ & 1 & 2 & 2 & $10.22 \mathrm{PM}$ & 1 & 2 & 0 & 3 \\
\hline $10.23 \mathrm{AM}$ & 0 & 4 & 1 & 10.23AM & 3 & 2 & 3 & $10.23 \mathrm{AM}$ & 4 & 2 & 2 & 8 \\
\hline 10.24PM & 0 & 1 & 0 & 10.24PM & 1 & 1 & 0 & 10.24PM & 1 & 0 & 2 & \\
\hline 10.25AM & 3 & 1 & 0 & 10.25AM & 2 & 0 & 1 & 10.25AM & 0 & 0 & 1 & 1 \\
\hline $10.26 \mathrm{PM}$ & 1 & 1 & 0 & $10.26 \mathrm{PM}$ & 1 & 1 & 1 & $10.26 \mathrm{PM}$ & 1 & 1 & 1 & 3 \\
\hline 10.27AM & 0 & 2 & 1 & 10.27AM & 1 & 3 & 1 & 10.27AM & 6 & 3 & 4 & 13 \\
\hline 10.28PM & 2 & 1 & 0 & 10.28PM & 2 & 5 & 1 & 10.28PM & 2 & 5 & 0 & 7 \\
\hline $10.29 \mathrm{AM}$ & 3 & 0 & 2 & -10.29AM & 1 & 4 & 2 & 10.29AM & 3 & 2 & 1 & 6 \\
\hline 10.30PM & 1 & 1 & $*^{*}{ }^{1}$ & $+410.30 \mathrm{PM}^{-1}$ & $\gamma^{\prime}$ & $-f \sim$ & -2 & $310.30 \mathrm{PM}$ & 0 & 1 & 1 & 2 \\
\hline
\end{tabular}

Firstly we aggregated the activity data and convert them into quantitative data. Since we classified outdoor activities into Pass, Stroll, and Stay categories, all the activities observed were classified into the three categories before calculation. Then activity data were separately tabulated, and total amount of users (10 times) were added up (Fig. 5).

In this way, we extracted quantitative activity data for every subspace. Since the total observation time was varied from 100 to 200 minutes, we converted number of users into estimated number of users per hour. Besides, due to population disparities among different communities, we adjust the data according to community population. Herein we proposed an indicator named (DA) to discuss density of activities, calculated as following:

$$
D A_{n}=P_{n} / P
$$

Where $\mathrm{DA}_{n}$ : Density of activity of subspace N;

$P_{n}$ : Estimated number of users per hour in subspace N;

$P$ : Community population 
The unit of this indicator is ratio of the number of users to the total community population in one hour (\%/h). After calculated all the DA of Pass, Stroll, and Stay activities for every subspace, a series of DA data were obtained. The data then will be used to analyze the relationships between environmental factors and different types of outdoor activities.

\subsection{Accessibility}

Accessibility is proposed as the most fundamental level of outdoor activity needs. It links to outdoor activity that incorporates elements such as the length of paths on which to approach the spaces. An accumulative distance (AD) was proposed as a variable of accessibility, which was evaluated by summing all the shortest distances from every residential building to the subspace using formula as follow:

\section{$A D_{n}=\sum D_{m-n}$ \\ Where $A D_{n}$ : Accumulative distance of subspace $\mathrm{N}$; \\ $D_{m-n}$ : Shortest distance from building $M$ to subspace $N$}

The accumulative distance represents location of subspace within the community. Except location of subspace, the location of community entrances is also important for that they provide a connection to outside. Hence, visual step depth (VSD) to community entrances was developed as another variable of accessibility using space syntax method. UCL depthmap software was used to automatically generate the VSD data. Finally we obtained two series of data: AD and VSD for accessibility.

Correlation analysis between accessibility and density of activities (DA) was conducted to show the significance of variables. Table 3 shows the results of analysis.

We could figure out that $A D$ is fairly well correlated to Stroll activities, and AD may be not so important to Pass activities. Although $A D$ is not well correlated with Stay activity, we could not say the location of subspace within community is not working. One possible reason is that the range of distances is narrow due to similar size of selected communities, which is the limitation of this results. Besides, the visibility step depth (VSD) plays more significant role to outdoor activities. From this result, VSD seems to be better describer for outdoor activities, especially for Stroll activities.

Table 3: Relations between variables of accessibility and outdoor activities

\begin{tabular}{c|c|c}
\hline Variables (N=33) & Coefficient \\
\hline \multirow{2}{*}{ Accumulative distance (AD) } & Passing-by related code (Pass) & -0.19 \\
& Walking related code (Stroll) & -0.46 \\
& Staying related code (Stay) & -0.29 \\
\hline \multirow{2}{*}{ Visual step depth from community entrances } & Passing-by related code (Pass) & -0.48 \\
(VSD) & Walking related code (Stroll) & -0.57 \\
& Staying related code (Stay) & -0.48 \\
\hline
\end{tabular}

\subsection{Environment supports}


Environment supports is the next level after accessibility. Environment supports mean what certain functional part of space mean to certain activities. It contains spatial character and presence of facility supposed to be deeper level of outdoor activity needs.

Spatial character refers to land use and property. Indicators extracted should follow the rule that the description is supposed to support certain activities. We checked square area supposed to strongly support Stay activities. Square in this paper was defined as a place where at least two people can remain or do some activities. 3 meter is the critical value for discerning square. As we finished site maps in Auto CAD after intensive survey, we can calculate the square area of each subspace. A series of data of square area was obtained finally.

Facilities also need to be discussed. Seat capacity was proposed as an indicator which is associated with some Stay activities. We set up 0.6 meter width as the criteria for calculating seat capacity. Then the data about how many people the subspaces can let residents seat was obtained.

Similarly correlation analysis was conducted to show the significance of square area, and seat capacity to outdoor activities. Table 4 shows the results of analysis.

Table 4: Relations between variables of environment and outdoor activities

\begin{tabular}{c|c|c}
\hline Variables (N=33) & Coefficient \\
\hline \multirow{2}{*}{ Square area (SA) } & Passing-by related code (Pass) & 0.35 \\
& Walking related code (Stroll) & 0.61 \\
& Staying related code (Stay) & 0.69 \\
\hline \multirow{2}{*}{ Seat capacity (SC) } & Passing-by related code (Pass) & -0.04 \\
& Walking related code (Stroll) & 0.28 \\
& Staying related code (Stay) & 0.35 \\
\hline
\end{tabular}

We can see that square are quite significant to Stroll, especially to Stay activities. On the other side, the seat capacity is not well correlated to Pass, Stroll, and Stay activities. The sequences of significance of the two variables to different activities are the same, SA and SC are most important to Stay activities, and least important to Pass activities. However, square is more significant than seat to Stay activities.

\subsection{Comfort}

To the deeper level, once needs of accessibility, and environment supports have been met, comfort may be considered where people decide to do the activities. Take subspace $\mathrm{J} 2$ in community JH for example, we visualized the estimated users per hour of Stroll activities on map in the left diagram of Fig. 6 . The line width shows the number of users. We can see that users of Stroll activities are more on north path than south path. One of considerable reason is the feeling of warmness. It can be considered that people maybe feel cold under the shadow of building on the south path (middle, right diagrams of Fig.6). 

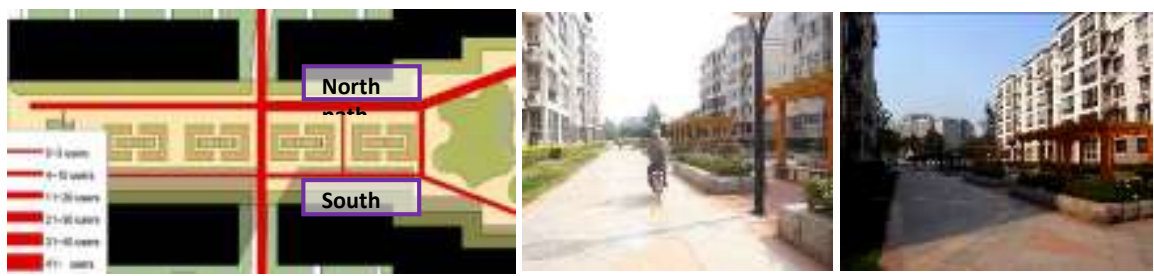

Figure 6: Stroll map of J2 (left) and images of activities on north path (middle) \& south path (right)

Whatever people do, they always like to stay in the warmer, cleaner, and greener places. All these factors are related to comfort. Comfort is proposed as a deepest level of outdoor activity needs, which reflects the convenience of doing activity, and the condition of variable elements such as the microclimate, greenery etc. It may influence more on the concrete locations of users.

\subsection{Conclusion}

The results of this study can be summarized as follows:

(1) The hierarchy of influential factors which was be placed within the context of the proposed social-ecological model is verified by empirical evidences. Accessibility is most fundamental factor, and environment supports is the less fundamental factor to outdoor activities. Comfort is the least fundamental one.

(2) Within these factors, there is a hierarchy of significance of variables. For accessibility, location of community entrances influence outdoor activities more than location of subspace. For environment supports, square is more important than seat to Stroll, and Stay activities.

(3) Until now we did not give quantitative evidence to explain the significance of comfort to outdoor activities. However, we can summarize that some items of comfort such as warmness, cleanness etc. are important to Stay activities, comfort may help to enrich the quality of outdoor activities.

On our route to explore the relationships between environmental factors and outdoor activities, firstly we had to cope with challenges such as how to deal with different concepts, and how to select survey sites. Finally we developed our criteria, selected suitable factors and variables. The results indicated influential factors and variables to different activities, which give us a direction of environment design for improving outdoor activities.

\section{Acknowledgement}


This research mainly based on field survey carried out in 2013 cooperated with Yuan Lab, Architecture School of Tianjin University, in Tianjin China.

\section{References}

Abd-Latif, R., Nora, M. M., Omar-Fauzee, M. S., Ahmad, A. R., \& Karim, F. (2012). Influence of physical environment towards leisure time physical activity (LTPA) among adolescents. Procedia - Social and Behavioral Sciences, 38, 234-242.

Alfonzo, M. A. (2005). To walk or not to walk? The hierarchy of walking needs. Environment \& Behavior, 37(6), 808836 .

Carlier, M., Delevoye-Turrell, Y., \& Dione, M. (2014). Cognitive benefits of physical activity increased when producing rhythmic actions. Procedia - Social and Behavioral Sciences, 126, 235-236.

Frank, L. D., Sallis, F. J., Conway, L. T., Chapman, E. J., Saelens, E.B., \& Bachman, W. (2006). Many pathways from land use to health, associations between neighborhood walkability and active transportation, body mass index, and air quality. Journal of the American Planning Association, 72, 75-87.

Franzini, L., Taylor, W., Elliott, N. M., Cuccaro, P., Tortolero, R. S., Gilliland, M.J., Grunbaum, J., \& Schuster, A. Mark. (2010). Neighborhood characteristics favorable to outdoor physical activity: Disparities by socioeconomic and racial/ethnic composition. Health \& Place, 16, 267-274.

Giles-Corti, B., \& Donovan, R. J. (2002). The relative influence of individual, social and physical environment determinants of physical activity. Social Science \& Medicine, 54, 1793-1812.

Gehl J., (2011). Life between Buildings: Using Public Space (6th ed.). Washington: Island press, 7-13.

Hanazato, T., \& Kim, M. (2011). Characteristics of inter-personal environment in the exterior space of super-highrise condominiums in Tsukishima, Tokyo. AlJ Journal of Technology and Design, 76(660), 271-280.

Honold, J., Wippert, P., \& Meer, E. V. D. (2014). Urban health resources: Physical and social constitutes of neighborhood social capital. Procedia - Social and Behavioral Sciences, 131, 491-496.

Kytta, Marketta. (2003). Children in Outdoor Contexts: Affordances and Independent Mobility in the Assessment of Environmental Child Friendliness (pp. 43-48). Helsinki University of Technology.

Laurens, J. M. (2012). Changing behavior and environment in a community-based program of the riverside community. Procedia - Social and Behavioral Sciences, 36, 372-382.

Mckenzie, T. L., \& Cohen, D. (2006). SOPARC: System for observing play and recreation in communities [PDF]. Retrieved from http://activelivingresearch.org/node/10654

Mohit, M. A., \& Azim, M. (2012). Assessment of residential satisfaction with public housing in Hulhumale', Maldives. Procedia - Social and Behavioral Sciences, 50, 756-770.

Nasir, R. A., Ahmad, S. S., \& Ahmed, A. Z. (2013). Physical activity and human comfort correlation in an urban park in hot and humid conditions. Procedia - Social and Behavioral Sciences, 105, 598-609.

Oloumi, S., Mahdavinejad, M., \& Namvarrad, A. (2011). Evaluation of outdoor environment from the viewpoint of children. Procedia - Social and Behavioral Sciences, 35, 431-439. 
Yin, Q., \& Ohno, R. / Asian Journal of Behavioural Studies (AjBeS), 3(12) Jul / Aug 2018 (p.103-114)

Schoggen, Phil. (1968). Behavior Settings: A revision and extension of Rogger G. Barker's 'Ecological Psychology' (pp. 2-3). Stanford University Press.

Shamsuddin, S., Hassan, N. R. A., \& Bilyamin, S. F. I. (2012). Wakable environment in increasing the liveability of a city. Procedia - Social and Behavioral Sciences, 50, 167-178.

Zhang, H., \& Li, M.J., (2011). Environmental characteristics of children's neighbourhood activities. Asian Journal of Environment-Behaviour Studies, 2(4), 39-50. 